\title{
PARTIAL SUMS OF GENERALIZED BESSEL FUNCTIONS
}

\section{HALIT ORHAN AND NiHAT YAGMUR}

Abstract. Let $\left(g_{p, b, c}\right)_{n}(z)=z+\sum_{m=1}^{n} b_{m} z^{m+1}$ be the sequence of partial sums of generalized and normalized Bessel functions $g_{p, b, c}(z)=z+\sum_{m=1}^{\infty} b_{m} z^{m+1}$ where $b_{m}=\frac{(-c / 4)^{m}}{m !(\kappa)_{m}}$ and $\kappa:=$ $p+(b+1) / 2 \neq 0,-1,-2, \ldots$. The purpose of the present paper is to determine lower bounds for $\Re\left\{\frac{g_{p, b, c}(z)}{\left(g_{p, b, c}\right)_{n}(z)}\right\}, \Re\left\{\frac{\left(g_{p, b, c}\right)_{n}(z)}{g_{p, b, c}(z)}\right\}, \Re\left\{\frac{g_{p, b, c}^{\prime}(z)}{\left(g_{p, b, c}\right)_{n}^{\prime}(z)}\right\}$ and $\Re\left\{\frac{\left(g_{p, b, c}\right)_{n}^{\prime}(z)}{g_{p, b, c}^{\prime}(z)}\right\}$. Further we give lower bounds for $\Re\left\{\frac{\mathbb{A}\left[g_{p, b, c}\right](z)}{\left(\mathbb{A}\left[g_{p, b, c}\right]\right)_{n}(z)}\right\}$ and $\Re\left\{\frac{\left(\mathbb{A}\left[g_{p, b, c}\right]\right)_{n}(z)}{\mathbb{A}\left[g_{p, b, c}\right](z)}\right\}$, where $\mathbb{A}\left[g_{p, b, c}\right]$ is the Alexander transform of $g_{p, b, c}$.

Mathematics subject classification (2010): Primary 30C45; Secondary 33C10.

Keywords and phrases: Partial sums, Analytic functions, Generalized Bessel functions, Bessel, modified Bessel and spherical Bessel functions.

\section{REFERENCES}

[1] J. W. AleXANDER, Functions which map the interior of the unit circle upon simple regions, Ann. of Math. 17 (1915), 12-22.

[2] A. BARICZ, Geometric properties of generalized Bessel functions, Publ. Math. Debrecen 73, 1-2 (2008), 155-178.

[3] A. BARICZ, Functional inequalities involving special functions, J. Math. Anal. Appl. 319 (2006), $450-459$.

[4] A. BARICZ, Functional inequalities involving special functions. II, J. Math. Anal. Appl. 327 (2007), $1202-1213$.

[5] A. BARICZ, Some inequalities involving generalized Bessel functions, Math. Inequal. Appl. 10 (2007), $827-842$.

[6] A. BARICZ AND S. Ponnus Amy, Starlikeness and convexity of generalized Bessel functions, Integral Transforms Spec. Funct. 21 (2010), 641-653.

[7] L. Brickman, D.J. Hallenbeck, T.H. MacGregor and D. Wilken, Convex hulls and extreme points of families of starlike and convex mappings, Trans. Amer. Math. Soc. 185 (1973), $413-$ 428.

[8] E. Deniz, H. Orhan And H.M. SRIVAStaVa, Some sufficient conditions for univalence of certain families of integral operators involving generalized Bessel functions, Taiwanese J. Math. 15, 2 (2011), 883-917.

[9] E. DENIZ, Convexity of integral operators involving generalized Bessel functions, Integral Transforms Spec. Funct. 1 (2012), 1-16.

[10] L.J. Lin AND S. OwA, On partial sums of the Libera integral operator, J. Math. Anal. Appl. 213, 2 (1997), 444-454.

[11] H. ORHAN AND E. GUNES, Neighborhoods and partial sums of analytic functions based on Gaussian hypergeometric functions, Indian J. Math. 51, 3 (2009), 489-510.

[12] S. OWA, H.M. SRIVASTAVA AND N. S Aito, Partial sums of certain classes of analytic functions, Int. J. Comput. Math. 81, 10 (2004), 1239-1256.

[13] T. Sheil-S Mall, A note on partial sums of convex schlicht functions, Bull. London Math. Soc. 2 (1970), 165-168. 
[14] H. Silverman, Partial sums of starlike and convex functions, J. Math. Anal. Appl. 209 (1997), 221227.

[15] E.M. Silvia, On partial sums of convex functions of order $\alpha$, Houston J. Math. 11 (1985), 397-404.

[16] G. N. WATson, A Treatise on the Theory of Bessel Functions, Second edition, Cambridge University Press, Cambridge, London and New York, 1944. 